\title{
Lemierre's Syndrome Variant with External Jugular Vein Thrombosis
}

\author{
Junji Takiguchi ${ }^{1}$, Hirokazu Sakamoto ${ }^{1}$ and Nobutaka Inoue ${ }^{2}$
}

Key words: Lemierre syndrome, external jugular vein, group C streptococcus

(Intern Med 56: 1271-1272, 2017)

(DOI: 10.2169/internalmedicine.56.8179)
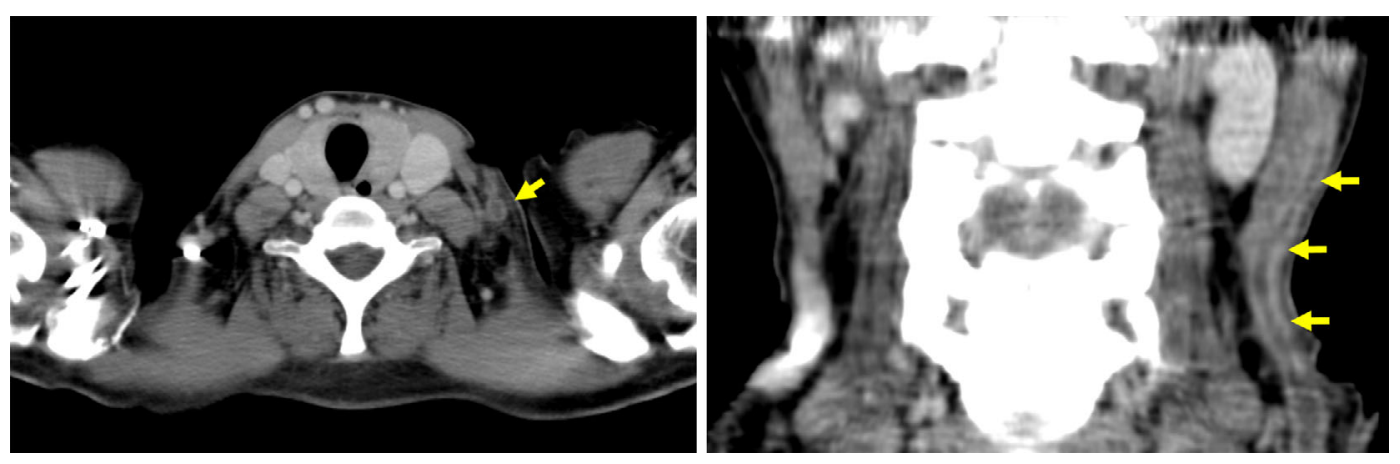

Picture 1.

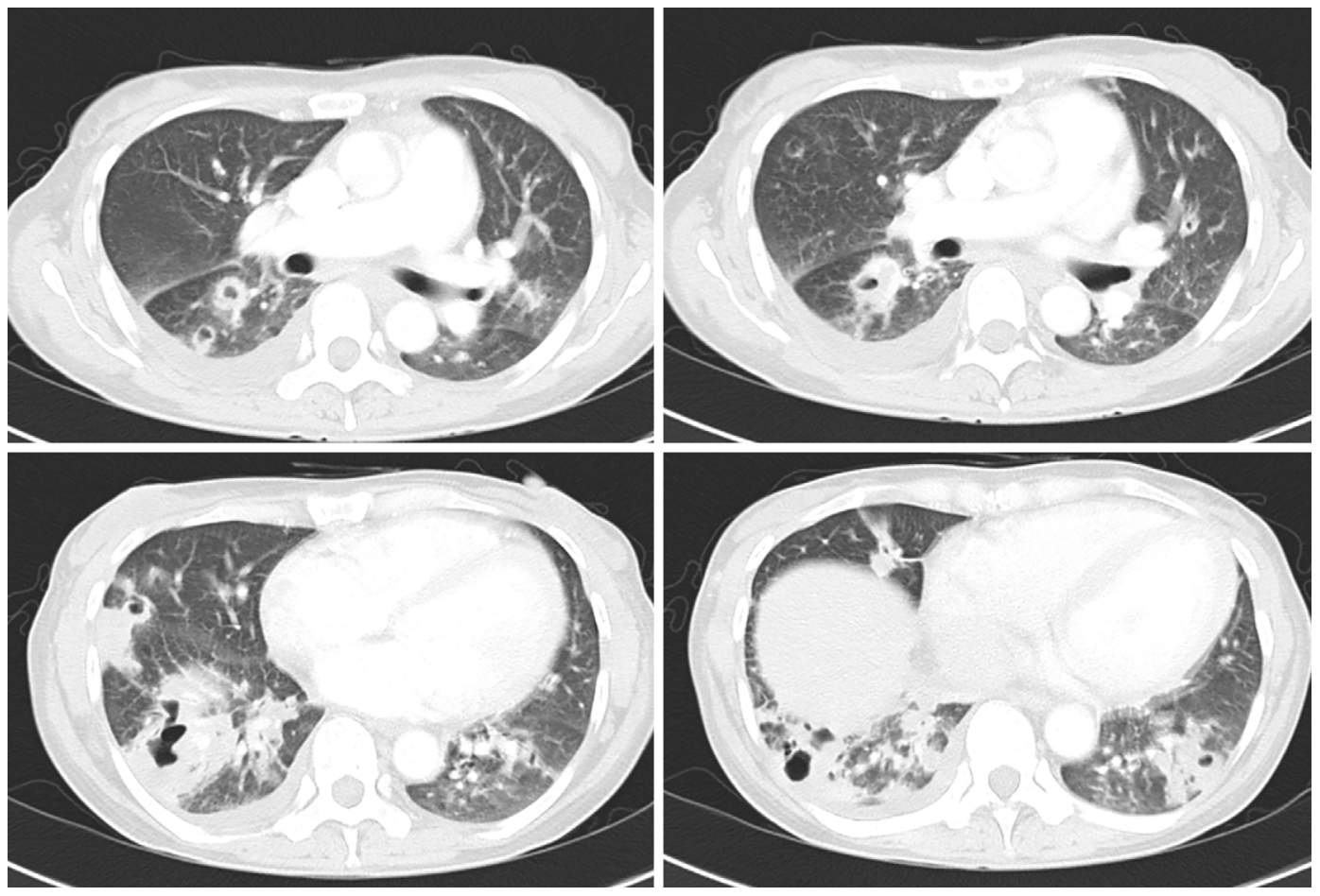

Picture 2.

${ }^{1}$ Department of Respiratory Medicine, Kobe Rosai Hospital, Japan and ${ }^{2}$ Department of Cardiovascular Medicine, Kobe Rosai Hospital, Japan Received for publication August 25, 2016; Accepted for publication August 30, 2016 Correspondence to Dr. Junji Takiguchi, j.takiguchi@kobeh.rofuku.go.jp 
A previously healthy 51-year-old woman developed a fever of $39^{\circ} \mathrm{C}$ accompanied by a sore throat and left jaw pain. After one week, her condition worsened, and she developed shock and multiple organ failure. She was admitted to her local hospital and then transferred to our hospital the next day, requiring mechanical ventilation for respiratory failure. Blood cultures revealed the growth of group C Streptococcus. Contrast-enhanced computed tomography revealed thrombosis of the left external jugular vein (Picture 1). There were multiple cavitary consolidations in both lungs, likely septic emboli (Picture 2). All of the findings were consistent with Lemierre's syndrome. The patient was treated with antibiotics, and she completely recovered. Lemierre's syndrome typically involves thrombosis of the internal jugular vein that develops after oropharyngeal infection with Fusobacterium necrophorum (1). We herein report a rare case of Lemierre's syndrome involving thrombosis in the external jugular vein caused by group C Streptococcus infection.

The authors state that they have no Conflict of Interest (COI).

\section{Reference}

1. Kuppalli K, Livorsi D, Talati NJ, Osborn M. Lemierre's syndrome due to Fusobacterium necrophorum. Lancet Infect Dis 12: 808$815,2012$.

The Internal Medicine is an Open Access article distributed under the Creative Commons Attribution-NonCommercial-NoDerivatives 4.0 International License. To view the details of this license, please visit (https://creativecommons.org/licenses/ by-nc-nd/4.0/).

(C) 2017 The Japanese Society of Internal Medicine http://www.naika.or.jp/imonline/index.html 